\title{
Initiation and completion rates for latent tuberculosis infection treatment: a systematic review
}

\author{
Andreas Sandgren ${ }^{1}$, Marije Vonk Noordegraaf-Schouten², Femke van Kessel ${ }^{2}$, Anke Stuurman²,
} Anouk Oordt-Speets ${ }^{2}$ and Marieke J. van der Werf ${ }^{3 *}$

\begin{abstract}
Background: Control of latent tuberculosis infection (LTBI) is an important step towards tuberculosis elimination. Preventive treatment will prevent the development of disease in most cases diagnosed with LTBI. However, low initiation and completion rates affect the effectiveness of preventive treatment. The objective was to systematically review data on initiation rates and completion rates for LTBI treatment regimens in the general population and specific populations with LTBI.

Methods: A systematic review of the literature (PubMed, Embase) published up to February 2014 was performed. Results: Forty-five studies on initiation rates and 83 studies on completion rates of LTBI treatment were found. These studies provided initiation rates (IR) and completion rates (CR) in people with $\mathrm{LTB}$ among the general population (IR 26-99 \%, CR 39-96 \%), case contacts (IR 40-95\%, CR 48-82 \%), healthcare workers (IR 47-98 \%, CR 17-79 \%), the homeless (IR 34-90\%, CR 23-71\%), people who inject drugs (IR 52-91\%, CR 38-89\%), HIV-infected individuals (IR 67-92 \%, CR 55-95\%), inmates (IR 7-90\%, CR 4-100\%), immigrants (IR 23-97\%, CR 7-86\%), and patients with comorbidities (IR 82-93\%, CR 75-92\%). Generally, completion rates were higher for short than for long LTBI treatment regimens.
\end{abstract}

Conclusion: Initiation and completion rates for LTBI treatment regimens were frequently suboptimal and varied greatly within and across different populations.

Keywords: Tuberculosis, Latent tuberculosis, Treatment initiation, Treatment completion, Risk groups

\section{Background}

In the European Union and European Economic Area (EU/EEA) 65 thousand cases of tuberculosis (TB) were reported in 2013, of which $77 \%$ had pulmonary TB [1]. Cases with pulmonary TB produce microscopic droplets when coughing, sneezing, or spitting which can infect other individuals [2]. Exposure to Mycobacterium tuberculosis may result in latent TB infection (LTBI), a state in which the host immune system controls the replication of the bacillus to the extent that the progression to TB disease is prevented [3, 4]. In a later phase, LTBI may progress to $\mathrm{TB}$ disease, especially if the immune system is compromised [3,5]. Given that one-third of

\footnotetext{
* Correspondence: marieke.vanderwerf@ecdc.europa.eu

${ }^{3}$ Tomtebodavägen 11a, 17165 Solna, Sweden

Full list of author information is available at the end of the article
}

the world population is estimated to be latently infected with TB, there is a huge reservoir for the development of future TB disease [6].

As long as a $M$. tuberculosis reservoir exists in individuals with LTBI, elimination of TB will not be feasible. Thus, the control of LTBI is an important step towards TB elimination. In addition to TB case detection and treatment, TB is controlled by identifying individuals who are latently infected with $M$. tuberculosis and offering them treatment that will prevent the development of TB disease, especially in high-income countries [7-9].

Several LTBI treatment regimens have shown effectivenesss [10]. However, adherence to these treatment regimens was sometimes low and differed between treatment regimens and populations $[8,11-18]$. Numerous reasons for low adherence have been reported, such as (fear of) 
side effects of the treatment, lack of symptomatic disease and thus lack of motivation for taking preventive treatment, or low risk perception of progression to active TB $[11,17,19]$.

Incorporating programmatic LTBI control into the national and EU/EEA strategies to fight TB is likely to be of value for all EU/EEA Member States. Therefore, the European Centre for Disease Prevention and Control (ECDC) aims to provide EU/EEA Member States and candidate countries with scientific advice and guidance on programmatic LTBI control. In order to collect the evidence base for developing the ECDC guidance a series of systematic reviews have been performed. This was done in collaboration with World Health Organization (WHO) who used the same evidence base for the development of the WHO guidelines on LTBI control [20] launched in early 2015. One important aspect for LTBI control is to ensure adherence to and completeness of the preventive treatment. Therefore, a systematic literature review was performed to assess initiation and completion rates of LTBI treatment and to identify determinants and interventions for adherence and completion, in the general and in specific populations with LTBI. In this article we present the results of the initiation and completion rates for recommended preventive treatments.

\section{Methods}

A systematic literature review was performed according to a review protocol and following the Cochrane guidelines. The aim of the systematic review was to provide answers to the following research questions: 1) What is the LTBI treatment initiation rate and the completion rate for each recommended LTBI treatment regimen; 2) What are determinants of LTBI treatment initiation, adherence, and completion; 3) What are the interventions with demonstrated efficacy or effectiveness to improve LTBI treatment initiation, adherence and completion in individuals who are eligible for LTBI treatment. Due to the extensive results, the results for review question 1 are presented in this article and the results for review questions 2 and 3 will be presented separately.

\section{Eligibility criteria}

PICO (Population-Intervention-Comparator-Outcome) questions were formulated based on the review questions (see Additional file 1: PICO questions). Only primary articles describing randomised controlled trials (RCTs), non-randomised prospective comparative studies of interventions, prospective longitudinal observational studies, and retrospective studies were included in this review. Systematic reviews were not included; however the reference lists of relevant systematic reviews were screened to find primary articles that were not found via our literature search. Studies in individuals eligible for LTBI treatment were considered relevant. Eligibility for LTBI treatment was defined as "being diagnosed with LTBI". There was no required minimum study duration or number of subjects, except for studies in the general population diagnosed with LTBI that also presented data stratified for specific populations (e.g. case contacts, immigrants etc.). Since these studies were primarily aimed at the total population, and sampling strategies were applied accordingly, data for the specific populations were only extracted when such a population consisted of at least 30 subjects. Studies were considered to be conducted in the general population when they did not specifically focus on certain risk groups. For an article to be included in the review, baseline data (e.g. population characteristics) must be presented, LTBI had to be defined in the study (e.g. as "positive tuberculin skin tests (greater of equal $10 \mathrm{~mm}$ ) and negative chest radiographs") and the LTBI treatment regimen had to be specified, and for studies presenting completion rates, a definition for "completion" had to be provided. Studies did not have to apply a specific definition for LTBI or completion to be included. Adherence rates that met the definition of "completion" (e.g. "full adherence" or "adherence for nine months") were interpreted as completion rates. If individuals whose completion status was pending by the end of a study were included in the completion rate, the rate was recalculated to exclude these individuals. Studies that included only case contacts who received chemoprophylaxis irrespective of whether or not LTBI was diagnosed were excluded from this review.

\section{Information sources and search strategy}

We searched the databases PubMed and Embase. Search strings were composed for 1) LTBI, 2) LTBI treatment, and 3) initiation, adherence, completion and implementation. A fourth search string was composed to exclude animal studies (see Additional file 2: Search strings). No geographical, time, or language limits were applied, however only full-text articles in English, French, Spanish, German, and Dutch were reviewed. The search was carried out on February $3^{\text {rd }}$, 2014 for all literature published up to that date. Output from the searched databases was exported to Endnote version X4.0.2.

\section{Study selection}

Articles were selected by a three-step selection procedure based on 1) screening of title and abstract, 2) screening of full-text article, and 3) final screening during the dataextraction phase. One-hundred percent of the title and abstract selection and critical appraisal of the full-text articles was done in duplicate by two independent researchers; the results were compared and discussed and any doubts were resolved by a third researcher. 


\section{Risk of bias assessment}

The risk of bias of each included full-text article was assessed with standardised, study-design specific, quality appraisal forms following the risk of bias assessment proposed by the Cochrane Collaboration [21]. A few additional aspects, not mentioned in the Cochrane Collaboration, were considered when evaluating the quality of the articles, i.e. the adequacy of recall assessment and reporting, whether confidence intervals were provided, and for retrospective studies, the adequacy of the method of retrospective selection of the population. Each aspect was evaluated as high risk of bias, moderate or unclear risk of bias, or low risk of bias. Because of the descriptive nature of the review question, risk of bias was only assessed for aspects of the individual studies, without providing an overall level of quality for each individual study. As review question 1 does not deal with the effects of health interventions and treatment and populations vary widely between studies, risk of bias was also not assessed across the evidence base per outcome.

\section{Data extraction}

Evidence tables were compiled by two researchers and reviewed by a third researcher. The data extraction was done in duplicate for $15 \%$ of the included articles, no major differences were found. Evidence tables were created for different populations with LTBI: 1) general population (primarily unselected individuals with LTBI at clinics), 2) case contacts, 3) healthcare workers, 4) the homeless, 5) people who inject drugs (PWID), 6) human immunodeficiency virus (HIV)-infected individuals, 7) inmates, 8) immigrants, and 9) patients with comorbidities, e.g. patients with rheumatoid arthritis or patients with hematologic malignancies. The definitions of completion were those used in the individual studies; there were differences in definitions between studies. Study results were sorted by study design and split by duration of the LTBI treatment regimen, i.e. short ( $\leq$ four months), long (>four months), or short and long combined when no data were presented for short and long LTBI treatment separately.

\section{Synthesis of results}

Meta-analysis is performed in accordance with GRADE methodology and results are reported in accordance with the Preferred Reporting Items for Systematic Reviews and Meta-Analyses (PRISMA) statement. For data visualisation, forest plots of initiation and completion rates were created for the identified populations in Excel 2010 [22]. The MetaXL 2.1 add-in in Excel was used to calculate $95 \%$ confidence intervals around initiation and completion rates. We planned to calculate pooled rates, however this was not done for the first review question, because of the large heterogeneity of the included articles.

\section{Results}

\section{Results of the review process}

The search resulted in 2536 unique hits; 115 relevant articles were included for all review questions (see Fig. 1). For review question 1, a total of 95 unique articles were found, including 43 prospective studies and 52 retrospective studies. Of these articles, 45 provided information on initiation rates of LTBI treatment regimens and 83 on completion rates. An overview of the study characteristics, initiation and/or completion rates, and the quality aspects of the risk of bias assessment of the included studies are presented in Additional file 3: Study characteristics, outcomes, and quality aspects.

\section{Initiation and completion rates}

Most study populations in the included articles consisted of individuals from the general population diagnosed with LTBI, case contacts or immigrants with LTBI (Table 1; Additional file 3: Study characteristics, outcomes, and quality aspects). In prospective studies, initiation and completion rates were most often presented for long treatment regimens and in retrospective studies rates were most frequently reported for either long treatment regimens or for short and long treatment regimens combined.

\section{Initiation rates}

Overall, twenty prospective studies [18, 19, 23-40] that reported initiation rates were found (Table 1; Additional file 3: Study characteristics, outcomes, and quality aspects). Initiation rates varied considerably among populations with LTBI, ranging from 26 to $99 \%$ in the general population (four studies [18, 23-25]) (Fig. 2), from 40 to $85 \%$ in case contacts (four studies [25-28]), from 34 to $90 \%$ in the homeless (three studies [25, 29, 30]), from 52 to $91 \%$ in PWID (three studies [31-33]), from 90 to $92 \%$ in HIV-infected individuals (three studies [34-36]), and from 23 to $97 \%$ in immigrants (four studies [25, 38-40]) (Additional file 3: Study characteristics, outcomes, and quality aspects). Only one prospective study each reported an initiation rate in healthcare workers or inmates, the initiation rates for these groups were $98 \%$ [19] and $65 \%$ [37], respectively. No prospective studies that reported initiation rates were found for patients with comorbidities.

Twenty-five retrospective studies that reported initiation rates, mostly based on medical records, were found (Table 1; Additional file 3: Study characteristics, outcomes, and quality aspects). There was considerable overlap in the ranges of initiation rates reported in prospective studies and retrospective studies.

\section{Completion rates}

In total, 39 prospective studies reporting completion rates were identified [12, 18, 23-27, 30-32, 34-62]. Completion rates ranged from 46 to $95 \%$ in the general 


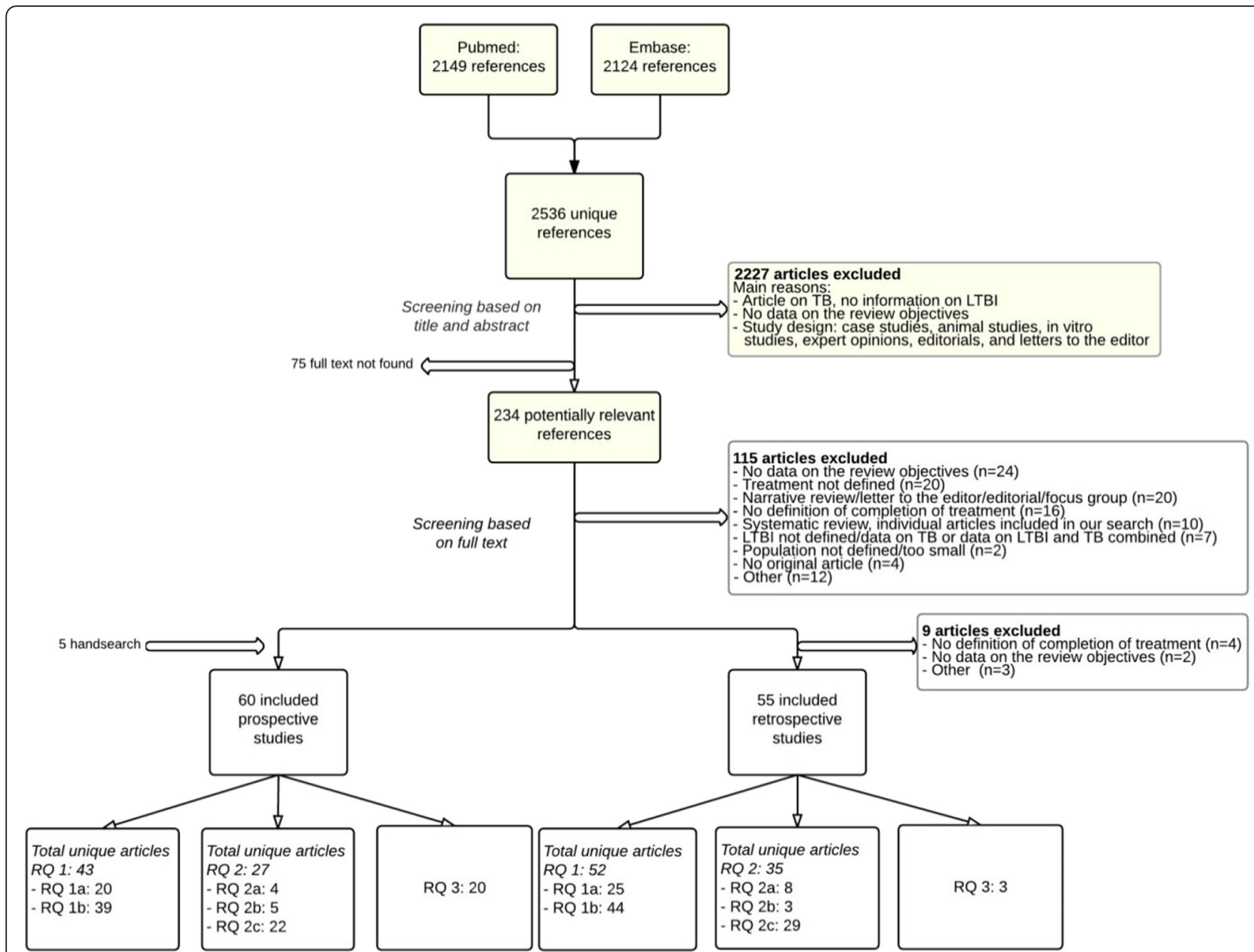

Fig. 1 Flow chart of selection process. RQ: review question. LTBI: latent tuberculosis infection; TB: tuberculosis. Review question 1a: What is the initiation rate for each recommended LTBI treatment regimen?; Review question 1b: What is the completion rate for each recommended LTBI treatment regimen?; Review question 2a: What are the determinants of LTBI treatment initiation?; Review question 2b: What are the determinants of LTBI treatment adherence?; Review question 2c: What are the determinants of LTBI treatment completion?; Review question 3: In individuals who are eligible for LTBI treatment, what are the interventions with demonstrated efficacy or effectiveness to improve LTBI treatment initiation, adherence and completion?

population (thirteen studies [12, 18, 23-25, 41, 42, $46,47,49,50,57,60])$, from 53 to $82 \%$ in case contacts (six studies $[12,25-27,51,52]$ ), from 25 to $71 \%$ in the homeless (four studies $[18,25,30,60]$ ), from 38 to $89 \%$ in PWID (four studies [31, 32, 56, 58]), from 55 to $95 \%$ in HIV-infected individuals (eight studies $[18,34-36,44,48,54,55])$, from 4 to $48 \%$ in inmates (three studies [37, 53, 63]), and from 7 to $83 \%$ in immigrants (nine studies [12, 25, 38-40, 43, 45, 57, 59]). Only one study reported a completion rate in healthcare workers and patients with comorbidities, the completion rates for these groups were $44 \%$ [18] and $87 \%$ [61], respectively. In addition, 44 retrospective studies reporting completion rates were found (Table 1; Additional file 3: Study characteristics, outcomes, and quality aspects). Within-study comparisons show that the homeless had lower completion rates than other populations [18, 25, 64].
As for initiation rates, considerable overlap in the ranges of completion rates reported in prospective studies and retrospective studies appears to exist.

\section{Short versus long treatment regimens}

In most of the 27 studies that presented separate completion rates for patients that received short treatment regimens and for patients that received long treatment regimens, completion rates appear to be higher for the short treatment group (Fig. 3; Additional file 4: Forest plots). However, an exception to this observation was Clerk et al., who showed higher completion rates for long treatment regimens than shorter regimens $(67 \%$ vs $79 \%$ ) [65], and a small number of other studies that showed very similar completion rates between the two treatment groups $[48,52,66,67]$ in various populations with LTBI. Due to large heterogeneity across studies 
Table 1 Number of included studies and ranges of initiation and completion rates per study population

\begin{tabular}{|c|c|c|c|c|c|c|}
\hline \multirow[t]{2}{*}{ Study population } & \multicolumn{2}{|c|}{ Short treatment regimens } & \multicolumn{2}{|c|}{ Long treatment regimens } & \multicolumn{2}{|c|}{$\begin{array}{l}\text { Short/long treatment regimens } \\
\text { combined }\end{array}$} \\
\hline & $n$ & Range rates (\%) & $n$ & Range rates (\%) & $n$ & Range rates (\%) \\
\hline \multicolumn{7}{|l|}{ Initiation rates } \\
\hline \multicolumn{7}{|c|}{ Prospective studies ( $n=20$ unique articles; some present data for more than one population and more than one treatment regimen) } \\
\hline General & $1[23]$ & 86 & $2[18,24]$ & 44-99 & $1[25]$ & 26 \\
\hline Case contacts & 0 & - & 3 [26-28] & $40-85$ & $1[25]$ & 53 \\
\hline Healthcare workers & $1[19]$ & 98 & 0 & - & 0 & - \\
\hline Homeless & 0 & - & $2[29,30]$ & $76-90$ & $1[25]$ & 34 \\
\hline PWID & 0 & - & 3 [31-33] & $52-91$ & 0 & - \\
\hline HIV infected & 0 & - & $2[34,35]$ & $90-92$ & $1[36]$ & 91 \\
\hline Inmates & 0 & - & $1[37]$ & 65 & 0 & - \\
\hline Immigrants & 0 & - & 3 [38-40] & $77-97$ & $1[25]$ & 23 \\
\hline $\begin{array}{l}\text { Patients with } \\
\text { comorbidities }\end{array}$ & 0 & - & 0 & - & 0 & - \\
\hline
\end{tabular}

Retrospective studies ( $n=25$ unique articles; some present data for more than one population and more than one treatment regimen)

\begin{tabular}{|c|c|c|c|c|c|c|}
\hline General & 0 & - & 4 [89-92] & $82-98$ & $5[16,78,93-95]$ & $53-83$ \\
\hline Case contacts & 0 & - & $1[96]$ & 81 & $5[13,78,97-99]$ & 74-95 \\
\hline Healthcare workers & 0 & - & $1[100]$ & 92 & $\begin{array}{l}4 \\
{[78,94,101,102]}\end{array}$ & $47-89$ \\
\hline Homeless & 0 & - & 0 & - & 0 & - \\
\hline PWID & 0 & - & 1 [103] & 56 & 0 & - \\
\hline HIV infected & 0 & - & 1 [104] & 67 & 0 & - \\
\hline Inmates & 0 & - & 0 & - & $2[80,105]$ & $7-90$ \\
\hline Immigrants & 0 & - & $2[106,107]$ & $78-84$ & $3[16,93,94]$ & $57-82$ \\
\hline $\begin{array}{l}\text { Patients with } \\
\text { comorbidities }\end{array}$ & 1 [108] & 93 & 1 [109] & 82 & 0 & - \\
\hline
\end{tabular}

Completion rates

Prospective studies ( $n=39$ unique articles; some present data for more than one population and more than one treatment regimen)

\begin{tabular}{|c|c|c|c|c|c|c|}
\hline General & $\begin{array}{l}10[12,23,25,41,42, \\
46,47,49,50,60]\end{array}$ & $61-95$ & $\begin{array}{l}10[12,18,24,25,41 \\
42,46,47,50,57]\end{array}$ & $46-76$ & 0 & - \\
\hline Case contacts & $2[51,52]$ & $71-82$ & $4[26,27,51,52]$ & $53-73$ & $2[12,25]$ & $60-64$ \\
\hline Healthcare workers & 0 & - & $1[18]$ & 44 & 0 & - \\
\hline Homeless & $1[60]$ & 71 & $2[18,30]$ & $25-33$ & $1[25]$ & 44 \\
\hline PWID & 0 & - & $4[31,32,56,58]$ & $38-89$ & 0 & - \\
\hline HIV infected & $6[36,44,48]$ & $62-95$ & $\begin{array}{l}8[18,34-36,44,48,54, \\
55]\end{array}$ & $55-89$ & 0 & - \\
\hline Inmates & $1[53]$ & 48 & $3[37,53,62]$ & $4-38$ & 0 & - \\
\hline Immigrants & $2[43,59]$ & $72-80$ & $8[38-40,43,45,57]$ & $7-83$ & $2[12,25]$ & $61-79$ \\
\hline $\begin{array}{l}\text { Patients with } \\
\text { comorbidities }\end{array}$ & $1[61]$ & 87 & 0 & - & 0 & - \\
\hline
\end{tabular}

Retrospective studies ( $n=44$ unique articles; some present data for more than one population and more than one treatment regimen)

\begin{tabular}{|c|c|c|c|c|c|c|}
\hline General & $\begin{array}{l}14[14-17,65-67,78, \\
79,81-83,110,111]\end{array}$ & $56-93$ & $\begin{array}{l}23[14-16,64-67,78, \\
79,81-83,89-92,112-118]\end{array}$ & 39-96 & 1 [93] & 54 \\
\hline Case contacts & $3[13,14,17]$ & $63-69$ & $4[13,14,113,116]$ & $56-78$ & $\begin{array}{l}5[78,82,97, \\
98,119]\end{array}$ & $48-81$ \\
\hline Healthcare workers & 0 & - & $2[100,113]$ & $17-75$ & $3[15,78,101]$ & $40-79$ \\
\hline
\end{tabular}


Table 1 Number of included studies and ranges of initiation and completion rates per study population (Continued)

\begin{tabular}{|c|c|c|c|c|c|c|c|}
\hline Homeless & $1[120]$ & 44 & $1[64]$ & 23 & 0 & - & 2 \\
\hline PWID & 0 & - & 1 [103] & 55 & 0 & - & 1 \\
\hline HIV infected & 0 & - & $2[14,104]$ & $55-66$ & 0 & - & 2 \\
\hline Inmates & $4[80,120]$ & $48-100$ & $2[80,121]$ & $23-68$ & 0 & - & 3 \\
\hline Immigrants & $4[14,16,17,122]$ & $60-85$ & $\begin{array}{l}11[14,16,64,89,91,92, \\
106,113,116,123,124]\end{array}$ & $38-86$ & $\begin{array}{l}5[15,65 \\
79,82,93]\end{array}$ & $53-69$ & 18 \\
\hline $\begin{array}{l}\text { Patients with } \\
\text { comorbidities }\end{array}$ & 1 [108] & 92 & 1 [125] & 75 & 0 & - & 2 \\
\hline
\end{tabular}

HIV human immunodeficiency virus, $n$ number of included studies, $N$ total number of included studies, PWID people who inject drugs

and the fact that most studies were not designed to specifically assess the effect of treatment duration on completion, no pooled analysis was performed to determine if there was a statistically significant association between treatment duration and completion rates.

\section{Discussion}

This is, to our knowledge, the first systematic review to comprehensively explore both initiation and completion rates of LTBI treatment worldwide. In total, evidence from 95 studies has been reviewed. Forty-five studies reported on initiation rates and 83 on completion rates, covering nine different population types with LTBI. There was wide variation in initiation and completion rates; the initiation rates ranged from 7 to $99 \%$ and the completion rates ranged from 4 to $100 \%$ across the different population groups. These rates should be interpreted taking into account the variety of treatment options (i.e. choice of regimen, duration, self-administered or observed).

\section{Risk groups}

The population for which most studies were identified was the general population diagnosed with LTBI. Though this population consisted primarily of unselected individuals with LTBI at clinics, it was very diverse, mainly due to the varying proportion of specific populations, such as immigrants, across clinics. Generally, two types of risk groups could be distinguished: groups with higher risk of TB infection, but without an increased risk of progression to TB (e.g. health care workers, inmates, and the homeless) [68-70] and groups with LTBI who are at higher risk of progression to active TB (e.g. HIV-infected individuals, patients with comorbidities) [71-74]. Case contacts appear to have both a higher risk of TB infection and a higher risk of progression to active TB due to recent infection $[68,75]$. The initiation rates and completion rates of LTBI treatment appeared slightly higher in the groups with higher risk of progression of LTBI to active $\mathrm{TB}$ than in the groups with higher risk of $\mathrm{TB}$

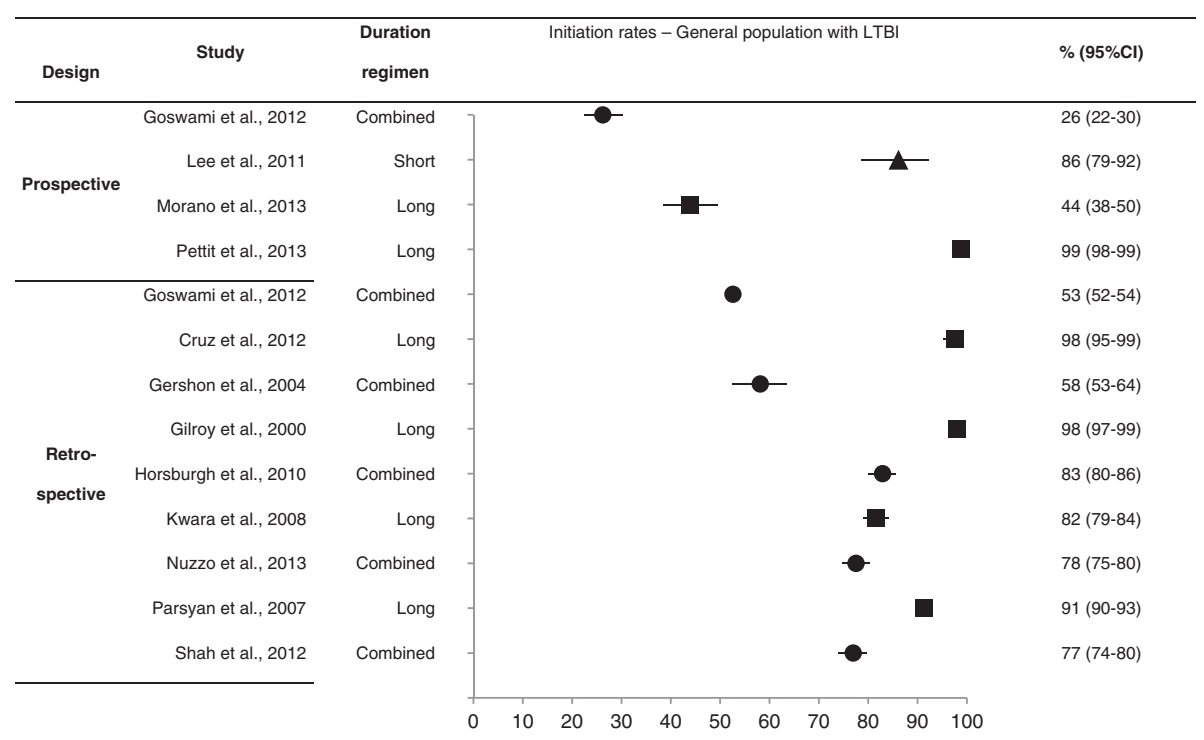

Fig. 2 Forest plots with ranges of initiation rates in the general population diagnosed with LTBI. LTBI: latent tuberculosis infection; Circle: combined, square: long, triangle: short 


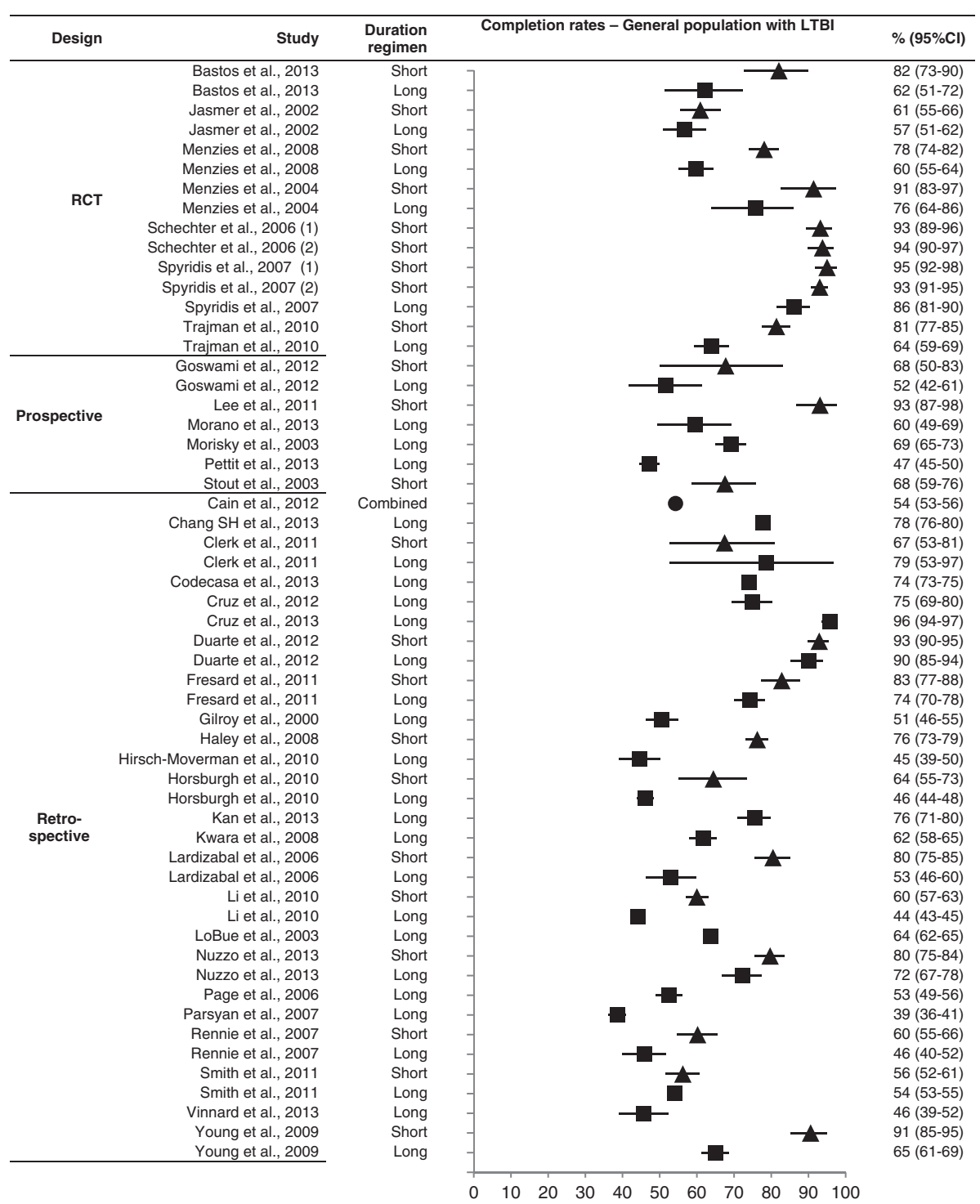

Fig. 3 Forest plot with completion rates in the general population diagnosed with LTBI. LTBI: latent tuberculosis infection; Circle: combined, square: long, triangle: short

infection. Care has to be taken when comparing findings between studies, due to differences within populations, in setting and in methodology.

Hirsch-Moverman et al. [11] reviewed studies in the United States and Canada published between 1997 and 2007 and presented completion rates of LTBI treatment that are in line with the results found in our review. Overall, 20 of the 60 studies that were included in their review were also included in ours; differences are due to the fact that we did not include studies that did not provide a definition for completion, did not specify the type of treatment or did not define LTBI.

Al-Darraji et al. [76] reviewed completion rates of treatment with isoniazid in inmates with LTBI, from studies published between 1966 and January 2011. Four of the sixteen studies they included were also included in our review. Both the presented completion rate of isoniazid treatment during incarceration and after release from jail appeared slightly higher than the completion rates of long LTBI treatment regimens in inmates found in our review.

\section{Short and long treatment regimens}

Short LTBI treatment most frequently consisted of four months of rifampicin or two months of rifampicin and pyrazinamide, though other combinations of rifampicin, isoniazid, rifabutin and pyrazinamide were also administered for two to four months. Currently, the combination of rifampicin with pyrazinamide is not generally offered to persons with LTBI as it has been associated 
with hepatotoxicity [77]. Long LTBI treatment consisted of isoniazid regimens, usually for six or nine months and often for twelve months in the case of concurrent HIVinfection. Only three studies presented initiation rates for short treatment regimens, therefore initiation rates between short and long treatment regimens could not be compared.

A considerable number of prospective articles presented completion rates for both short and long treatment regimens, especially in the general population diagnosed with LTBI and in HIV-infected individuals with LTBI. Most results of within-study comparisons of short and long treatments [13-16, 78-83] indicated higher completion rates for shorter regimens, although in two studies rates were comparable for short and long treatment regimens $[66,67]$. In one study lower completion rates were reported for short treatment than for longer treatments [65] due to adverse effects. It should be kept in mind that the type of drugs used in short and long LTBI treatment regimens varied considerably between studies and within populations.

Hirsch-Moverman et al. [11] also reviewed data on completion rates of short (rifampicin or rifampicin in combination with pyrazinamide) and long (isoniazid) treatment regimens within studies and found a higher percentage of completion among short treatments in all included studies, although the difference was not always significant. Ziakas et al. [84] systematically reviewed the literature for studies that compared four months of rifampicin with nine months of isoniazid, published up to July 2009, and included four studies in a meta-analysis. These four studies were also included in this review. They concluded that four months of rifampicin was associated with a significant reduction in the risk of non-completion [84]. Sharma et al. [85] conducted a systematic review on RCTs worldwide among HIV-negative people at risk of active TB that compared rifampicin monotherapy or rifamycincombination therapy with isoniazid monotherapy. Their meta-analysis of five trials, of which two were included in our review, compared rifampicin (three or four months) with isoniazid (six months) and showed that significantly more people completed the shorter course. Two more of their meta-analyses compared isoniazid in combination with rifampicin (three months; two trials) or rifampicin in combination with pyrazinamide (two months; three trials, one of which was included in our review) with isoniazid (six months) and found that there was no difference in completion rates [85].

By comparing completion rates between short and long LTBI treatment we do not take into account any effect of the treatment regimen on completion rate, e.g. due to different side effect patterns. The effect of different treatment regimens for preventing active $\mathrm{TB}$, and thus indirectly taking into account completion, has been compared by
Stagg et al. [10] and was part of the same evidence base collection as our systematic review.

\section{Limitations}

Studies without a definition for "completion" were excluded from this review. Still, the definition of completion varied considerably between studies, and this heterogeneity complicated comparison of completion rates between studies. Definitions used varied from "completed four months of rifampicin" [81] to "picked up nine months of isoniazid within twelve months" [25] and "took at least $80 \%$ of the prescribed medication within twenty weeks" [15]. Also, the quality of the definitions of "completion" varied throughout the included studies and the distinction between definitions for adherence and completion was not always obvious. Besides, the quality of the definition of "completion" is closely linked to the way treatment adherence is assessed, which varied from self-reported adherence (least reliable) [35], dispense of medication [58], pill counts [52], urine tests [43], to Directly Observed Treatment (DOT; most reliable) [62]. Furthermore, it was not always clear whether and to what extent the classification of a patient as having completed treatment was influenced by the time that a patient needed to take all the doses. Finally, some patients may have discontinued treatment due to toxicity. In our analysis, this is included in non completion. Discontinuation because of side effects will influence the effectiveness of latent TB infection treatment but it will need other efforts than voluntary discontinuation of treatment.

In addition, rate calculations varied across included studies; different rules were applied for in- and exclusion into the denominator to calculate the initiation and/or completion rates. All these differences between studies and unclarities hampered the analysis.

Within our review, no distinction was made between studies that looked at a priori defined risk groups versus studies that identified risk factors in a non-selected group of individuals with LTBI. Also, population characteristic or settings of risk groups may vary between studies, for example immigrants in the United States might differ from immigrants in Europe with respect to their origin $[86,87]$. In addition, it should be noted that individuals with LTBI might belong to multiple risk groups, as overlap between the groups exists; however, most studies did not specify if there was any overlap between risk groups.

\section{Conclusions}

The goal of LTBI treatment is to eradicate $M$. tuberculosis from the body and to reduce the risk of progression to active TB disease [88]. Only treatment can clear the bacteria from the body, and therefore individuals with LTBI who do not initiate treatment contribute to the persistence of the TB reservoir. Clinical benefit to the individual with 
LTBI and the success of control programs is subject to completion of LTBI treatment.

This systematic review found that initiation and completion rates for LTBI treatment regimens were frequently suboptimal and varied greatly within and across different populations. Population groups with a higher risk of TB infection, but without an increased risk of progression to TB (e.g. health care workers, inmates, and the homeless) seemed at slightly higher risk of low initiation and completion rates. However, the limited number of studies found for certain LTBI treatment regimens and study populations, and the variation in types of risk populations, settings, treatment regimens and study methodologies in the included studies make it difficult to draw firm conclusions.

Considering the sub-optimal rates of completion, implementing interventions to improve the adherence and completion rates in groups most at risk of developing active TB seems relevant to make LTBI treatment more effective and decrease the spread of TB.

\section{Ethics approval and consent to participate}

Not applicable.

\section{Consent for publication}

Not applicable.

\section{Availability of data and materials}

The datasets supporting the conclusions of this article are included within the article and its additional files.

\section{Additional files}

Additional file 1: PICO questions. (DOC $45 \mathrm{~kb}$ )

Additional file 2: Search strings. (DOC $29 \mathrm{~kb}$ )

Additional file 3: Study characteristics, outcomes, and quality aspects of risk of bias assessment of articles on initiation and completion rates of LTBI treatment regimens. (DOC $680 \mathrm{~kb}$ )

Additional file 4: Forest plots. (DOC $396 \mathrm{~kb})$

\section{Abbreviations}

ECDC: European Centre for Disease Prevention and Control; EU/EEA: European Union and European Economic Area; HIV: human immunodeficiency virus; LTBI: latent TB infection; PICO: Population-Intervention-Comparator-Outcome; PWID: people who inject drugs; RCTs: randomised controlled trials; TB: tuberculosis; WHO: World Health Organization.

\section{Competing interests}

The authors declare that they have no competing interests.

\section{Authors' contributions}

MVN, AS and MvdW designed the review and search strategy. FvK and ALS searched the literature, selected the studies, extracted and analyzed data. MVN and AO controlled the quality of the review process. MVN, AO and MvdW assessed the quality of data analysis. ALS, AO, MVN and AS drafted the manuscript. MVN, AO, FvK, ALS, AS and MvdW edited the manuscript. All authors read and approved the final manuscript.

\section{Acknowledgements}

Not applicable.

\section{Funding}

This work was performed under the ECDC Framework Contract FWC/ECDC/ 2013/005 Specific Contract No. 1 ECD.4065 awarded to the consortium consisting of Pallas, health research and consultancy and the Department of Public Health, Erasmus MC, and Service contract ECD.5000 of OJ/02/05/2014-PROC/2014/015 awarded to Pallas, health research and consultancy.

\section{Author details}

${ }^{1}$ Former Surveillance and Response Section, European Centre for Disease Prevention and Control (ECDC), Stockholm 171 65, Sweden. ${ }^{2}$ Pallas, Health Research and Consultancy B.V., Rotterdam 3001, The Netherlands.

${ }^{3}$ Tomtebodavägen 11a, 17165 Solna, Sweden.

Received: 16 February 2016 Accepted: 7 May 2016

Published online: 17 May 2016

References

1. European Centre for Disease Prevention and Control/WHO Regional Office for Europe. Tuberculosis surveillance and monitoring in Europe 2015. Stockholm: ECDC; 2015.

2. Fox GJ, Barry SE, Britton WJ, Marks GB. Contact investigation for tuberculosis: a systematic review and meta-analysis. Eur Respir J. 2013;41:140-56.

3. Barry 3rd CE, Boshoff HI, Dartois $V$, et al. The spectrum of latent tuberculosis: rethinking the biology and intervention strategies. Nat Rev Microbiol. 2009; 7:845-55.

4. Lin PL, Flynn JL. Understanding latent tuberculosis: a moving target. J Immunol. 2010;185:15-22.

5. Lillebaek T, Dirksen A, Baess I, Strunge B, Thomsen VO, Andersen AB. Molecular evidence of endogenous reactivation of Mycobacterium tuberculosis after 33 years of latent infection. J Infect Dis. 2002;185:401-4.

6. Dye C, Scheele S, Dolin P, Pathania V, Raviglione MC. Consensus statement. Global burden of tuberculosis: estimated incidence, prevalence, and mortality by country. WHO Global Surveillance and Monitoring Project. JAMA. 1999:282:677-86.

7. National Institute for Health and Care Excellence. Clinical diagnosis and management of tuberculosis, and measures for its prevention and control. NICE clinical guideline. Manchester: NICE; 2011. p. 67

8. Canadian Tuberculosis Standards, 7th Edition. In: Menzies D, editor. Canadian Tuberculosis Standards. 7th ed. Ottawa: Canadian Thoracic Society, The Canadian Lung Association, Public Health Agency of Canada; 2014

9. Centers for Disease Control and Prevention. Targeted tuberculin testing and treatment of latent tuberculosis infection. MMWR Recomm Rep. 2000:49:1-54.

10. Stagg HR, Zenner D, Harris RJ, Munoz L, Lipman MC, Abubakar I. Treatment of latent tuberculosis infection: a network meta-analysis. Ann Intern Med. 2014;161:419-28.

11. Hirsch-Moverman Y, Daftary A, Franks J, Colson PW. Adherence to treatment for latent tuberculosis infection: systematic review of studies in the US and Canada. Int J Tuberc Lung Dis. 2008;12:1235-54.

12. Trajman A, Long R, Zylberberg D, Dion MJ, Al-Otaibi B, Menzies D. Factors associated with treatment adherence in a randomised trial of latent tuberculosis infection treatment. Int J Tuberc Lung Dis. 2010;14:551-9.

13. Anger $\mathrm{HA}$, Proops $\mathrm{D}$, Harris $\mathrm{TG}$, et al. Active case finding and prevention of tuberculosis among a cohort of contacts exposed to infectious tuberculosis cases in New York City. Clin Infect Dis. 2012;54:1287-95.

14. Li J, Munsiff SS, Tarantino T, Dorsinville M. Adherence to treatment of latent tuberculosis infection in a clinical population in New York City. Int J Infect Dis. 2010;14:e292-7.

15. Page KR, Sifakis F, Montes de Oca R, et al. Improved adherence and less toxicity with rifampin vs isoniazid for treatment of latent tuberculosis: a retrospective study. Arch Intern Med. 2006;166:1863-70.

16. Nuzzo JB, Golub JE, Chaulk P, Shah M. Analysis of Latent Tuberculosis Infection Treatment Adherence Among Refugees and Other Patient Groups Referred to the Baltimore City Health Department TB Clinic, February 2009March 2011. J Immigr Minor Health. 2015:17(1):56-65.

17. Haley CA, Stephan S, Vossel LF, Sherfy EA, Laserson KF, Kainer MA. Successful use of rifampicin for Hispanic foreign-born patients with latent tuberculosis infection. Int J Tuberc Lung Dis. 2008;12:160-7. 
18. Pettit AC, Bethel J, Hirsch-Moverman Y, Colson PW, Sterling TR. Female sex and discontinuation of isoniazid due to adverse effects during the treatment of latent tuberculosis. J Infect. 2013;67:424-32.

19. Shukla SJ, Warren DK, Woeltje KF, Gruber CA, Fraser VJ. Factors associated with the treatment of latent tuberculosis infection among health-care workers at a midwestern teaching hospital. Chest. 2002;122:1609-14.

20. World Health Organization. Guidelines on the management of latent tuberculosis infection. 2015. p. 38

21. Higgins JP, Altman DG, Gotzsche PC, et al. The Cochrane Collaboration's tool for assessing risk of bias in randomised trials. BMJ. 2011;343:d5928.

22. Neyeloff $J$, Fuchs SC, Moreira LB. Meta-analyses and Forest plots using a microsoft excel spreadsheet: step-by-step guide focusing on descriptive data analysis. BMC Res Notes. 2012;5:52.

23. Lee SH, Yim JJ, Kim HJ, et al. Adverse events and development of tuberculosis after 4 months of rifampicin prophylaxis in a tuberculosis outbreak. Epidemiol Infect. 2012;140:1028-35.

24. Morano JP, Walton MR, Zelenev A, Bruce RD, Altice FL. Latent tuberculosis infection: screening and treatment in an urban setting. J Community Health. 2013;38:941-50.

25. Goswami ND, Gadkowski LB, Piedrahita C, et al. Predictors of latent tuberculosis treatment initiation and completion at a U.S. public health clinic: a prospective cohort study. BMC Public Health. 2012;12:468.

26. Machado Jr A, Finkmoore B, Emodi K, et al. Risk factors for failure to complete a course of latent tuberculosis infection treatment in Salvador, Brazil. Int J Tuberc Lung Dis. 2009;13:719-25.

27. Centers for Disease Control and Prevention (CDC). Transmission of Mycobacterium tuberculosis associated with failed completion of treatment for latent tuberculosis infection-Chickasaw County, Mississippi, June 1999March 2002. MMWR Morb Mortal Wkly Rep. 2003;52:222-4.

28. Rutherford ME, Ruslami R, Anselmo M, et al. Management of children exposed to mycobacterium tuberculosis: a public health evaluation in west java, indonesia. Bull World Health Organ. 2013;91:932-41.

29. Bock NN, Metzger BS, Tapia JR, Blumberg HM. A tuberculin screening and isoniazid preventive therapy program in an inner-city population. Am J Respir Crit Care Med. 1999;159:295-300.

30. Lashley M. A targeted testing program for tuberculosis control and prevention among Baltimore city's homeless population. Public Health Nurs. 2007;24:34-9.

31. Brassard P, Bruneau J, Schwartzman K, Senecal M, Menzies D. Yield of tuberculin screening among injection drug users. Int J Tuberc Lung Dis. 2004;8:988-93.

32. Scholten JN, Driver CR, Munsiff SS, et al. Effectiveness of isoniazid treatment for latent tuberculosis infection among human immunodeficiency virus (HIV)-infected and HIV-uninfected injection drug users in methadone programs. Clin Infect Dis. 2003;37:1686-92.

33. Snyder DC, Paz EA, Mohle-Boetani JC, Fallstad R, Black RL, Chin DP. Tuberculosis prevention in methadone maintenance clinics. Effectiveness and cost-effectiveness. Am J Respir Crit Care Med. 1999;160:178-85.

34. Bark CM, Morrison CS, Salata RA, et al. Acceptability of treatment of latent tuberculosis infection in newly HIV-infected young women in Uganda. Int J Tuberc Lung Dis. 2010;14:1647-9.

35. Oni T, Tsekela R, Kwaza B, et al. A recent HIV diagnosis is associated with non-completion of Isoniazid Preventive Therapy in an HIV-infected cohort in Cape Town. PLoS One. 2012;7:e52489.

36. Narita M, Kellman M, Franchini DL, McMillan ME, Hollender ES, Ashkin D. Short-course rifamycin and pyrazinamide treatment for latent tuberculosis infection in patients with HIV infection: the 2-year experience of a comprehensive community-based program in Broward County, Florida. Chest. 2002;122:1292-8.

37. Nolan CM, Roll L, Goldberg SV, Elarth AM. Directly observed isoniazid preventive therapy for released jail inmates. Am J Respir Crit Care Med. 1997;155:583-6.

38. Minodier $P$, Lamarre V, Carle ME, Blais D, Ovetchkine P, Tapiero B. Evaluation of a school-based program for diagnosis and treatment of latent tuberculosis infection in immigrant children. J Infect Public Health 2010;3:67-75.

39. Trauer JM, Krause VL. Assessment and management of latent tuberculosis infection in a refugee population in the Northern Territory. Med J Aust. 2011;194:579-82

40. Young J, Edick T, Klee D, O'Connor ME. Successful treatment of pediatric latent tuberculosis infection in a community health center clinic. Pediat Infect Dis J. 2012;31:e147-51.
41. Bastos ML, Menzies D, Belo MT, et al. Changes in QuantiFERON(R)-TB Gold In-Tube results during treatment for tuberculous infection. Int J Tuberc Lung Dis. 2013;17:909-16.

42. Jasmer RM, Saukkonen JJ, Blumberg HM, et al. Short-course rifampin and pyrazinamide compared with isoniazid for latent tuberculosis infection: a multicenter clinical trial. Ann Intern Med. 2002;137:640-7.

43. Jimenez-Fuentes MA, de Souza-Galvao ML, Mila Auge C, Solsona Peiro J, AltetGomez MN. Rifampicin plus isoniazid for the prevention of tuberculosis in an immigrant population. Int J Tuberc Lung Dis. 2013;17:326-32.

44. Matteelli A, Olliaro P, Signorini L, et al. Tolerability of twice-weekly rifabutinisoniazid combinations versus daily isoniazid for latent tuberculosis in HIVinfected subjects: a pilot study. Int J Tuberc Lung Dis. 1999;3:1043-6.

45. Matteelli A, Casalini C, Raviglione MC, et al. Supervised preventive therapy for latent tuberculosis infection in illegal immigrants in Italy. Am J Respir Crit Care Med. 2000;162:1653-5.

46. Menzies D, Dion MJ, Rabinovitch B, Mannix S, Brassard P, Schwartzman K. Treatment completion and costs of a randomized trial of rifampin for 4 months versus isoniazid for 9 months. Am J Respir Crit Care Med. 2004; 170:445-9.

47. Menzies D, Long R, Trajman A, et al. Adverse events with 4 months of rifampin therapy or 9 months of isoniazid therapy for latent tuberculosis infection: a randomized trial. Ann Intern Med. 2008;149:689-97.

48. Rivero A, Lopez-Cortes L, Castillo R, et al. Randomized clinical trial investigating three chemoprophylaxis regimens for latent tuberculosis infection in HIVinfected patients. Enferm Infecc Microbiol Clin. 2007;25:305-10.

49. Schechter M, Zajdenverg R, Falco G, et al. Weekly rifapentine/isoniazid or daily rifampin/pyrazinamide for latent tuberculosis in household contacts. Am J Respir Crit Care Med. 2006;173:922-6.

50. Spyridis NP, Spyridis PG, Gelesme A, et al. The effectiveness of a 9-month regimen of isoniazid alone versus 3 - and 4-month regimens of isoniazid plus rifampin for treatment of latent tuberculosis infection in children: results of an 11-year randomized study. Clin Infect Dis. 2007:45:715-22.

51. Sterling TR, Villarino ME, Borisov AS, et al. Three months of rifapentine and isoniazid for latent tuberculosis infection. N Engl J Med. 2011:365:2155-66.

52. Tortajada C, Martinez-Lacasa J, Sanchez F, et al. Is the combination of pyrazinamide plus rifampicin safe for treating latent tuberculosis infection in persons not infected by the human immunodeficiency virus? Int J Tuberc Lung Dis. 2005:9:276-81.

53. Bock NN, Rogers T, Tapia JR, Herron GD, DeVoe B, Geiter L. Acceptability of short-course rifampin and pyrazinamide treatment of latent tuberculosis infection among jail inmates. Chest. 2001;119:833-7.

54. Golub JE, Pronyk P, Mohapi L, et al. Isoniazid preventive therapy, HAART and tuberculosis risk in HIV-infected adults in South Africa: a prospective cohort. AIDS. 2009;23:631-6.

55. Hiransuthikul N, Nelson KE, Hiransuthikul P, Vorayingyong A, Paewplot R. INH preventive therapy among adult HIV-infected patients in Thailand. Int J Tuberc Lung Dis. 2005;9:270-5.

56. Lorvick J, Thompson S, Edlin BR, Kral AH, Lifson AR, Watters JK. Incentives and accessibility: a pilot study to promote adherence to TB prophylaxis in a high-risk community. J Urban Health. 1999;76:461-7.

57. Morisky DE, Ebin VJ, Malotte CK, Coly A, Kominski G. Assessment of tuberculosis treatment completion in an ethnically diverse population using two data sources. Implications for treatment interventions. Eval Health Prof. 2003;26:43-58.

58. Sadaphal P, Astemborski J, Graham NM, et al. Isoniazid preventive therapy, hepatitis $C$ virus infection, and hepatotoxicity among injection drug users infected with Mycobacterium tuberculosis. Clin Infect Dis. 2001;33:1687-91.

59. Sarivalasis A, Bodenmann P, Langenskiold E, Lutchmaya-Flick C, Daher O, Zellweger JP. High rate of completion of preventive therapy for latent tuberculosis infection among asylum seekers in a Swiss Canton. Swiss Med Wkly. 2013;143:w13860.

60. Stout JE, Engemann JJ, Cheng AC, Fortenberry ER, Hamilton CD. Safety of 2 months of rifampin and pyrazinamide for treatment of latent tuberculosis. Am J Respir Crit Care Med. 2003:167:824-7.

61. Valls $V$, Ena J. Short-course treatment of latent tuberculosis infection in patients with rheumatic conditions proposed for anti-TNF therapy. Clin Rheumatol. 2014;34:29

62. White MC, Tulsky JP, Goldenson J, Portillo CJ, Kawamura M, Menendez E. Randomized controlled trial of interventions to improve follow-up for latent tuberculosis infection after release from jail. Arch Intern Med. 2002; 162:1044-50 
63. White MC, Tulsky JP, Menendez E, Goldenson J, Kawamura LM. Incidence of TB in inmates with latent TB infection: 5-year follow-up. Am J Prev Med. 2005;29:295-301.

64. LoBue PA, Moser KS. Use of isoniazid for latent tuberculosis infection in a public health clinic. Am J Respir Crit Care Med. 2003;168:443-7.

65. Clerk N, Sisson K, Antunes G. Latent tuberculosis: concordance and duration of treatment regimens. Br J Nurs. 2011;20:824-7.

66. Duarte $\mathrm{R}$, Carvalho A, Correia A. Two-month regimen of isoniazid, rifampin and pirazinamid for latent tuberculosis infection. Public Health. 2012;126:760-2.

67. Smith BM, Schwartzman K, Bartlett G, Menzies D. Adverse events associated with treatment of latent tuberculosis in the general population. CMAJ. 2011 183:E173-9.

68. Joshi R, Reingold AL, Menzies D, Pai M. Tuberculosis among health-care workers in low- and middle-income countries: a systematic review. PLoS Med. 2006;3:e494.

69. O'Grady J, Maeurer M, Atun R, et al. Tuberculosis in prisons: anatomy of global neglect. Eur Respir J. 2011;38:752-4.

70. Moss AR, Hahn JA, Tulsky JP, Daley CL, Small PM, Hopewell PC. Tuberculosis in the homeless. A prospective study. Am J Respir Crit Care Med. 2000;162:460-4.

71. Selwyn PA, Hartel D, Lewis VA, et al. A prospective study of the risk of tuberculosis among intravenous drug users with human immunodeficiency virus infection. N Engl J Med. 1989;320:545-50.

72. Gardam MA, Keystone EC, Menzies R, et al. Anti-tumour necrosis factor agents and tuberculosis risk: mechanisms of action and clinical management. Lancet Infect Dis. 2003;3:148-55.

73. Kamboj M, Sepkowitz KA. The risk of tuberculosis in patients with cancer. Clin Infect Dis. 2006;42:1592-5.

74. Narasimhan P, Wood J, Macintyre CR, Mathai D. Risk factors for tuberculosis. Pulm Med. 2013;2013:828939.

75. Centers for Disease Control and Prevention (CDC). Missed opportunities for prevention of tuberculosis among persons with HIV infection-selected locations, United States, 1996-1997. MMWR Morb Mortal Wkly Rep. 2000;49:685-7.

76. Al-Darraji HA, Kamarulzaman A, Altice FL. Isoniazid preventive therapy in correctional facilities: a systematic review. Int J Tuberc Lung Dis. 2012;16:871-9.

77. Centers for Disease Control and Prevention (CDC). Update: adverse event data and revised American Thoracic Society/CDC recommendations against the use of rifampin and pyrazinamide for treatment of latent tuberculosis infection-United States, 2003. MMWR Morb Mortal Wkly Rep. 2003:52:735-9.

78. Horsburgh Jr CR, Goldberg S, Bethel J, et al. Latent TB infection treatment acceptance and completion in the United States and Canada. Chest. 2010; 137:401-9.

79. Lardizabal A, Passannante M, Kojakali F, Hayden C, Reichman LB. Enhancement of treatment completion for latent tuberculosis infection with 4 months of rifampin. Chest. 2006;130:1712-7.

80. Lopez G, Wood M, Ayesta FJ. 10 years of innovation in the treatment of latent tuberculosis infection: a comparison between standard and short course therapies in directly observed therapy. Rev Esp Sanid Penit. 2011;13:3-14.

81. Fresard I, Bridevaux PO, Rochat T, Janssens JP. Adverse effects and adherence to treatment of rifampicin 4 months vs isoniazid 6 months for latent tuberculosis: a retrospective analysis. Swiss Med Wkly. 2011;141:w13240.

82. Rennie TW, Bothamley GH, Engova D, Bates IP. Patient choice promotes adherence in preventive treatment for latent tuberculosis. Eur Respir J. 2007; 30:728-35.

83. Young $H$, Wessolossky $M$, Ellis J, Kaminski M, Daly JS. A retrospective evaluation of completion rates, total cost, and adverse effects for treatment of latent tuberculosis infection in a public health clinic in central massachusetts. Clin Infect Dis. 2009:49:424-7.

84. Ziakas PD, Mylonakis E. 4 months of rifampin compared with 9 months of isoniazid for the management of latent tuberculosis infection: a metaanalysis and cost-effectiveness study that focuses on compliance and liver toxicity. Clin Infect Dis. 2009:49:1883-9.

85. Sharma SK, Sharma A, Kadhiravan T, Tharyan P. Rifamycins (rifampicin, rifabutin and rifapentine) compared to isoniazid for preventing tuberculosis in HIV-negative people at risk of active TB. Cochrane Database Syst Rev. 2013;7:CD007545.

86. Eurostat Press Office. Immigration in the EU27 in 2006 In: newsrelease E, ed. 2008.

87. Comparing Migrant Stock: The Foreign Born in Australia, Canada, and the United States by Region of Origin. 2014. Accessed 15 Dec 2014.

88. Denholm JT, McBryde ES. The use of anti-tuberculosis therapy for latent TB infection. Infect Drug Resist. 2010;3:63-72.
89. Cruz AT, Starke JR. Increasing adherence for latent tuberculosis infection therapy with health department-administered therapy. Pediatr Infect Dis J. 2012;31:193-5

90. Gilroy SA, Rogers MA, Blair DC. Treatment of latent tuberculosis infection in patients aged $>$ or $=35$ years. Clin Infect Dis. 2000;31:826-9.

91. Kwara A, Herold JS, Machan JT, Carter EJ. Factors associated with failure to complete isoniazid treatment for latent tuberculosis infection in Rhode Island. Chest. 2008;133:862-8.

92. Parsyan AE, Saukkonen J, Barry MA, Sharnprapai S, Horsburgh Jr CR. Predictors of failure to complete treatment for latent tuberculosis infection. J Infect. 2007; $54 \cdot 262-6$

93. Cain KP, Garman KN, Laserson KF, et al. Moving toward tuberculosis elimination: implementation of statewide targeted tuberculin testing in Tennessee. Am J Respir Crit Care Med. 2012;186:273-9.

94. Gershon AS, McGeer A, Bayoumi AM, Raboud J, Yang J. Health care workers and the initiation of treatment for latent tuberculosis infection. Clin Infect Dis. 2004:39:667-72

95. Shah M, DiPietro D, Greenbaum A, et al. Programmatic impact of QuantiFERON-TB Gold In-Tube implementation on latent tuberculosis diagnosis and treatment in a public health clinic. PLoS One. 2012;7:e36551.

96. Langenskiold E, Herrmann FR, Luong BL, Rochat T, Janssens JP. Contact tracing for tuberculosis and treatment for latent infection in a low incidence country. Swiss Med Wkly. 2008;138:78-84.

97. Chee CB, Teleman MD, Boudville IC, Do SE, Wang YT. Treatment of latent TB infection for close contacts as a complementary TB control strategy in Singapore. Int J Tuberc Lung Dis. 2004;8:226-31.

98. Grinsdale JA, Ho CS, Banouvong H, Kawamura LM. Programmatic impact of using QuantiFERON(R)-TB Gold in routine contact investigation activities. Int Juberc Lung Dis. 2011;15:1614-20.

99. Marks SM, Taylor Z, Qualls NL, Shrestha-Kuwahara RJ, Wilce MA, Nguyen CH. Outcomes of contact investigations of infectious tuberculosis patients. Am J Respir Crit Care Med. 2000:162:2033-8.

100. Balkhy HH, Miller TL, Ali S, et al. Compliance with postexposure screening and treatment of latent tuberculosis infection among healthcare workers in a tertiary care hospital in Saudi Arabia. Infect Control Hosp Epidemiol. 2014; 35:176-81.

101. Tavitian SM, Spalek VH, Bailey RP. A pharmacist-managed clinic for treatment of latent tuberculosis infection in health care workers. Am J Health Syst Pharm 2003;60:1856-61.

102. Xu Y, Schwartzman K. Referrals for positive tuberculin tests in new health care workers and students: a retrospective cohort study. BMC Public Health. 2010;10:28.

103. Golub JE, Astemborski J, Ahmed M, et al. Long-term effectiveness of diagnosing and treating latent tuberculosis infection in a cohort of HIVinfected and at-risk injection drug users. J Acquir Immune Defic Syndr. 2008;49:532-7.

104. Mugisha B, Bock N, Mermin J, et al. Tuberculosis case finding and preventive therapy in an HIV voluntary counseling and testing center in Uganda. Int J Tuberc Lung Dis. 2006;10:761-7.

105. Lincoln T, Brannan GL, Lynch V, et al. Completing tuberculosis prophylaxis in jail: targeting treatment and comparison of rifampin/pyrazinamide with isoniazid regimens. Int J Tuberc Lung Dis. 2004;8:306-11.

106. Ailinger RL, Black $P$, Nguyen N, Lasus H. Predictors of Adherence to Latent Tuberculosis Infection Therapy in Latino Immigrants. J Community Health Nurs. 2007:24:191-8.

107. Brassard P, Steensma C, Cadieux L, Lands LC. Evaluation of a school-based tuberculosis-screening program and associate investigation targeting recently immigrated children in a low-burden country. Pediatrics. 2006;117: e148-56.

108. Yun JW, Lim SY, Suh GY, et al. Diagnosis and treatment of latent tuberculosis infection in arthritis patients treated with tumor necrosis factor antagonists in Korea. J Korean Med Sci. 2007:22:779-83.

109. Stucchi RS, Boin IF, Angerami RN, Zanaga L, Ataide EC, Udo EY. Is isoniazid safe for liver transplant candidates with latent tuberculosis? Transplant Proc. 2012:44:2406-10.

110. Lee AM, Mennone JZ, Jones RC, Paul WS. Risk factors for hepatotoxicity associated with rifampin and pyrazinamide for the treatment of latent tuberculosis infection: experience from three public health tuberculosis clinics. Int J Tuberc Lung Dis. 2002;6:995-1000.

111. McElroy PD, ljaz K, Lambert LA, et al. National survey to measure rates of liver injury, hospitalization, and death associated with rifampin and 
pyrazinamide for latent tuberculosis infection. Clin Infect Dis. 2005;41: 1125-33.

112. Chang SH, Eitzman SR, Nahid P, Finelli ML. Factors associated with failure to complete isoniazid therapy for latent tuberculosis infection in children and adolescents. J Infect Public Health. 2014;7:145-52.

113. Codecasa $L R$, Murgia N, Ferrarese $M$, et al. Isoniazid preventive treatment: predictors of adverse events and treatment completion. Int J Tuberc Lung Dis. 2013;17:903-8.

114. Cruz AT, Starke JR. Twice-weekly therapy for children with tuberculosis infection or exposure. Int J Tuberc Lung Dis. 2013;17:169-74.

115. Hirsch-Moverman Y, Bethel J, Colson PW, Franks J, El-Sadr W. Predictors of latent tuberculosis infection treatment completion in the United States: an inner city experience. Int J Tuberc Lung Dis. 2010;14:1104-11.

116. Kan B, Kalin M, Bruchfeld J. Completing treatment for latent tuberculosis: patient background matters. Int J Tuberc Lung Dis. 2013;17:597-602.

117. Vinnard C, Gopal A, Linkin DR, Maslow J. Isoniazid toxicity among an older veteran population: a retrospective cohort study. Tuberc Res Treat. 2013; 2013:549473.

118. White MC, Gournis E, Kawamura M, Menendez E, Tulsky JP. Effect of directly observed preventive therapy for latent tuberculosis infection in San Francisco. Int J Tuberc Lung Dis. 2003;7:30-5.

119. Anibarro L, Casas S, Paz-Esquete J, et al. Treatment completion in latent tuberculosis infection at specialist tuberculosis units in Spain. Int J Tuberc Lung Dis. 2010;14:701-7.

120. Lobato MN, Reves RR, Jasmer RM, Grabau JC, Bock NN, Shang N. Adverse events and treatment completion for latent tuberculosis in jail inmates and homeless persons. Chest. 2005;127:1296-303.

121. Bandyopadhyay T, Murray H, Metersky ML. Cost-effectiveness of tuberculosis prophylaxis after release from short-term correctional facilities. Chest. 2002; 121:1771-5.

122. Priest DH, Vossel Jr LF, Sherfy EA, Hoy DP, Haley CA. Use of intermittent rifampin and pyrazinamide therapy for latent tuberculosis infection in a targeted tuberculin testing program. Clin Infect Dis. 2004;39:1764-71.

123. Ailinger RL, Dear MR. Adherence to tuberculosis preventive therapy among Latino immigrants. Public Health Nurs. 1998;15:19-24.

124. Ailinger RL, Moore JB, Nguyen N, Lasus H. Adherence to latent tuberculosis infection therapy among latino immigrants. Public Health Nurs. 2006;23:307-13.

125. Sanchez-Garcia EM, Gamallo R, Blanco-Moure A, Viejo MA, Amador L, Anibarro L. Toxicity and adherence to treatment for latent tuberculosis infection in patients with hematologic malignancies. Infection. 2013;41:903-7.

\section{Submit your next manuscript to BioMed Central and we will help you at every step:}

- We accept pre-submission inquiries

- Our selector tool helps you to find the most relevant journal

- We provide round the clock customer support

- Convenient online submission

- Thorough peer review

- Inclusion in PubMed and all major indexing services

- Maximum visibility for your research

Submit your manuscript at www.biomedcentral.com/submit 